Article

\title{
Leucettamols, Bifunctionalized Marine Sphingoids, Act as Modulators of TRPA1 and TRPM8 Channels
}

\section{Giuseppina Chianese ${ }^{1}$, Ernesto Fattorusso ${ }^{1, \dagger}$, Masteria Yunovilsa Putra ${ }^{1,2}$, Barbara Calcinai ${ }^{2}$, Giorgio Bavestrello ${ }^{3}$, Aniello Schiano Moriello ${ }^{4}$, Luciano De Petrocellis ${ }^{4}$, Vincenzo Di Marzo ${ }^{5}$ and Orazio Taglialatela-Scafati ${ }^{1, *}$}

1 Department of Natural Compounds Chemistry, University of Naples Federico II, Via Montesano 49, 80131 Napoli, Italy; E-Mails: g.chianese@unina.it (G.C.); mas_ter52@yahoo.co.id (M.Y.P.)

2 Department of Marine Science, Polytechnic University of Marche, Via Brecce Bianche, 60131 Ancona, Italy; E-Mail: b.calcinai@univpm.it

3 Department for the Study of the Territory and its Resources, University of Genoa, Corso Europa 26, 16132, Genova, Italy; E-Mail: g.bavestrello@univpm.it

4 Endocannabinoid Research Group, Istituto di Cibernetica-CNR, Via Campi Flegrei 34, 80078 Pozzuoli (Naples), Italy; E-Mails: a.schianomoriello@cib.na.cnr.it (A.S.M.);

1.depetrocellis@cib.na.cnr.it (L.D.P.)

5 Endocannabinoid Research Group, Istituto di Chimica Biomolecolare-CNR, Via Campi Flegrei 34, 80078 Pozzuoli (Naples), Italy; E-Mail: vdimarzo@icmib.na.cnr.it

$\uparrow$ Deceased on 7 July 2012.

* Author to whom correspondence should be addressed; E-Mail: scatagli@unina.it; Tel.: +39-081-678-509; Fax: +39-081-678-552.

Received: 30 August 2012; in revised form: 15 October 2012 / Accepted: 18 October 2012 / Published: 2 November 2012

\begin{abstract}
Leucettamols, bifunctionalized sphingoid-like compounds obtained from a marine sponge Leucetta sp., act as non-electrophilic activators of the TRPA1 channel and potent inhibitors of the icilin-mediated activation of the TRPM8 channel, while they are inactive on $\mathrm{CB}_{1}, \mathrm{CB}_{2}$ and TRPV1 receptors. Leucettamols represent the first compounds of marine origin to target TRPA1 and the first class of natural products to inhibit TRPM8 channels. The preparation of a small series of semi-synthetic derivatives revealed interesting details on the structure-activity relationships within this new chemotype of simple acyclic TRP modulators.
\end{abstract}


Keywords: leucettamols; TRP receptors; pain modulation

\section{Introduction}

The transient receptor potential (TRP) proteins are a superfamily of non selective cation channels (permeable to both monovalent and divalent cations) characterized by six transmembrane domains, a pore forming loop, and $\mathrm{COOH} / \mathrm{NH}_{2}$ termini located in the cytosol [1]. About thirty mammalian TRP channels have been identified and grouped into six main subfamilies: TRPC (canonical), TRPA (ankyrin), TRPV (vanilloid), TRPM (melastatin), TRPP (polycystin), TRPML (mucolipin) [2]. TRP channels are considered to be ubiquitous in the human organism and they are expressed practically in almost every tissue and cell type where they regulate several cell functions [3]. For example, some TRP channels have been demonstrated to be strongly involved in the mediation of pain, taste, hot or cold sensations and they can be considered as cellular sensors for external stimuli [4]. However, fifteen years after the cloning of the first TRP channel (TRPV1) [5], the detailed physiological role of these channels, as well as their involvement in human pathological conditions, is still yet to be fully disclosed. Only a few channelopathies have been identified [6] but there is evidence that a dysregulation in the TRP activity is implicated in the pathogenesis of many other diseases, thus TRP agonists/antagonists could provide interesting pharmacological options in several pathologies [7].

In view of their involvement in the detection of pain-evoking noxious stimuli, TRPA1 and TRPM8, along with TRPV1, are probably the most intensely investigated TRP channels. TRPA1 seems to play a great role in noxious cold perception and has been implicated in neuropathic and inflammatory pain [8]; consequently, it is an emerging target for novel analgesic and anti-inflammatory agents. TRPM8 is a neuronal sensor activated by innocuous cool and noxious cold temperatures [9] and plays a role in cold and mechanical allodynia arising from traumatic neuropathy, in conjunction with TRPA1 [10]. Recent studies have also shown that TRPM8 is markedly expressed in visceral organs, predominantly in prostate and liver [11] and, more importantly, it is highly upregulated in prostate cancer cells [12]. Some Authors have hypothesized that the TRPM8-mediated $\mathrm{Ca}^{2+}$ efflux may play a role in prostate tumour cell proliferation [13]. Thus, antagonism of TRPM8 activation could represent a novel and potentially useful approach for the treatment of painful conditions, such as cold allodynia and cold hyperalgesia, for which there continues to be a high unmet medical need, but it is also an innovative strategy for the treatment of urological disorder, especially prostate cancer, a major health problem in adult males.

In view of their incredible potential for biomedical and nutritional research, it is not surprising that recent years have witnessed an intense research activity aimed at finding specific ligands for the different TRP channels. Endogenous ligands such as arachidonic acid and linolenic acid derivatives activate TRP channels [14], while other lipid mediators, such as diacylglycerols, have been described to open some mammalian TRPC channels [15]. Natural products play a prominent role as TRP ligands [16] and many TRP channels are activated/antagonized by the so-called "chemestetical" secondary metabolites found in some natural sources, especially spices: for example allyl isothiocyanate (horseradish and wasabi), diallylthiosulfinate (garlic) and cinnamaldehyde (cinnamon) 
are activators of the sensory ion channel TRPA1 [17], menthol (mint) and eucalyptol (eucalyptus) activate the cold receptor TRPM8 [18], vanilloids as capsacin (chilli pepper) but also cannabidiol (hemp) stimulate TRPV1 [19]. In this latter case, it is interesting to note the existence of a close functional cross-talk between TRPV1 and cannabinoid (CB) receptors; indeed, TRPV1 and the related channel TRPV4 have been shown to be opened by the endocannabinoid anandamide, which also antagonizes TRPM8 channels [20]. Natural product ligands continue to be investigated as valuable leads for the deorphanisation of TRP ion channels since new TRP modulators are strongly needed both as tools for further biological studies on these multifunctional channels and as viable candidates for drug discovery.

We have been actively working in this field and have recently reported the identification of some TRP [21-24] and CB [25] ligands from natural sources, e.g., zerumbone and curcumin identified as TRPA1 ligands [23]. In this paper we now report that leucettamols A (1) and B (3) (Scheme 1), two-headed sphingoid-like compounds obtained from the marine sponge Leucetta sp., act as potent modulators of TRPA1 and TRPM8 channels, while they do not show any activity on CB and TRPV1 receptors. Some preliminary structure-activity relationships in this new chemotype of simple acyclic TRP modulators, deduced through the preparation of a small series of semi-synthetic derivatives, will be also discussed here.

Scheme 1. Chemical structures of leucettamols A (1) and B (3) and of their semi-synthetic analogues.
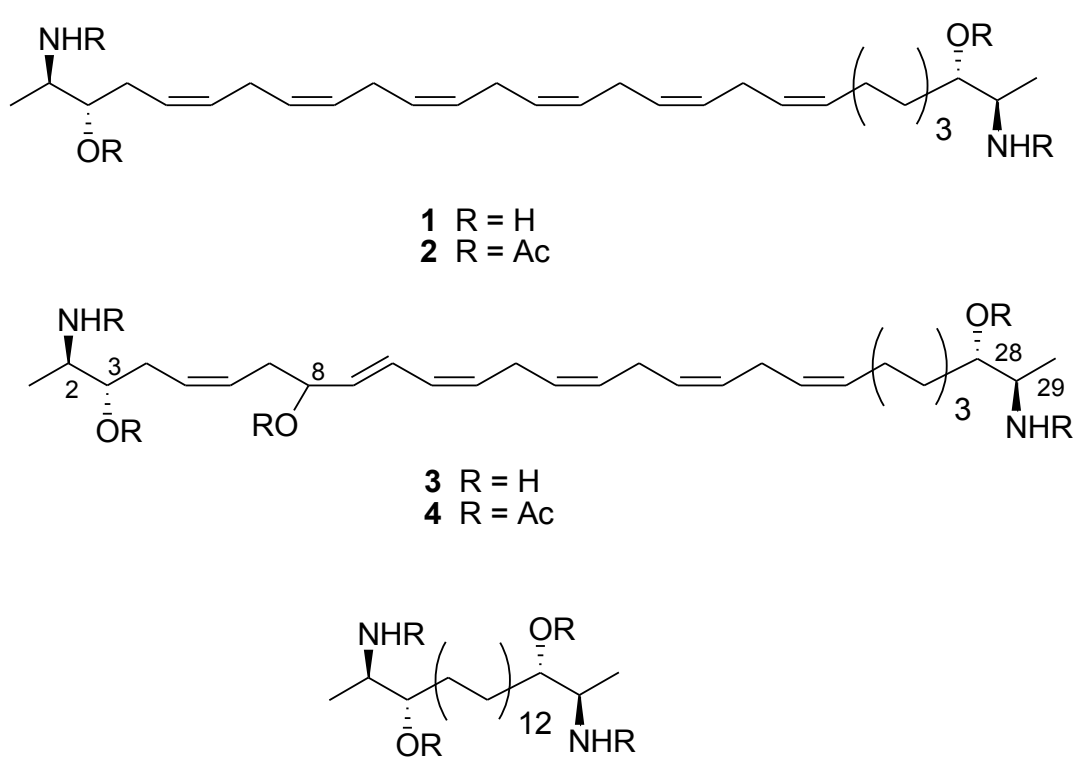

$$
\begin{array}{ll}
5 & R=H \\
6 & R=A c
\end{array}
$$

\section{Results and Discussion}

\subsection{Chemistry}

In the frame of our ongoing investigation of Indonesian invertebrates for bioactive secondary metabolites [26-28], we had the opportunity to analyze a specimen of the sponge Leucetta sp. (family Leucettidae, order Clathrinida), collected along the Island of Siladen, in the Bunaken Marine Park of 
Manado (North Sulawesi, Indonesia). The sponge (310 g wet weight) was extracted with $\mathrm{MeOH}$ and $\mathrm{CHCl}_{3}$ at room temperature and the combined organic extracts $(8.6 \mathrm{~g})$ were partitioned between $\mathrm{H}_{2} \mathrm{O}$ and EtOAc to give an acetate extract of $0.45 \mathrm{~g}$, while the water phase was further partitioned against $n$ - $\mathrm{BuOH}$, thus affording a butanol extract $(1.2 \mathrm{~g})$. This was chromatographed by MPLC (medium pressure liquid chromatography) over silica gel eluting with a gradient system of increasing polarity from EtOAc to $\mathrm{MeOH}$, and the obtained fractions were further purified by RP18 HPLC affording leucettamols A $(1,452.0 \mathrm{mg})$ and B $(3,45.5 \mathrm{mg})$ in the pure state. The structures of these compounds were assigned through comparison of their spectral data with those reported in the literature [29].

Leucettamols are $\mathrm{C}_{30}$ bifunctionalized sphingoid-like compounds first reported from the Micronesian Leucetta microrhaphis and then demonstrated to moderately inhibit the interaction of the ubiquitin enzyme Ubc13 and Uev1A, thus up-regulating the activity of the tumour suppressor p53 protein and qualifying as a possible anti-cancer leads [30]. In a recent paper, Molinski et al. have determined the absolute configurations at the four stereogenic centers of leucettamol A (1) as $2 R, 3 S, 28 S, 29 R$ by analysis of deconvoluted exciton coupled circular dichroism [31]. In the same paper, the authors also postulated that the co-occurring leucettamol B (3) should possess the same absolute configuration at the parallel stereogenic carbons, but they left undetermined the absolute configuration at C-8, suggesting an artifact origin for this stereocenter. In this regard, it should be considered that the organic extract obtained from Leucetta sp. did not appear to contain any regioisomer of leucettamol B, thus excluding "random" pattern of oxygenation. We tried to complete the stereostructural elucidation of 3 through application of the Mosher's method for secondary alcohols but, unfortunately, in the reaction conditions leucettamol $\mathrm{B}$ experienced a severe degradation which prevented any unambiguous stereochemical determination.

Standard acetylation (pyridine/acetic anhydride) of leucettamols A (1) and B (3) yielded the tetra-acetylated $\mathbf{2}$ and the penta-acetylated 4, respectively (Scheme 1). Compound $\mathbf{1}(34.0 \mathrm{mg}$ ) was also treated with palladium-charcoal in $\mathrm{EtOH}(6 \mathrm{~mL})$ under a hydrogen atmosphere for $18 \mathrm{~h}$ to afford, after filtration of the catalyst and HPLC purification, the saturated compound 5 (36.5 mg, 100\%). An aliquot of $5(8.0 \mathrm{mg})$ was then acetylated to give 6 in quantitative yields (Scheme 1).

\subsection{Activity at CB Receptors and TRP Channels}

Inspired by a certain structural resemblance of leucettamols with anandamide ( $N$-arachidonoyl ethanolamide), one of the main endogenous agonists of cannabinoid receptors, we decided to evaluate the affinity of 1-6 on these end-points. Leucettamols A and B and their semisynthetic analogues did not exhibit significant affinity for both $\mathrm{CB}_{1}$ and $\mathrm{CB}_{2}\left(K_{\mathrm{i}}>10 \mu \mathrm{M}\right.$, data not shown), with no difference between non-acetylated and acetylated analogues. Then, considering that anadamide also behaves as modulators toward some TRP channels (i.e., TRPV1 and TRPM8) [20], compounds 1-6 were also tested on the three most intensely investigated TRP channels (TRPV1, TRPA1, and TRPM8), which play an important role in the detection of painful stimuli. Within the six tested compounds only leucettamol B (3) showed a moderate $\left(\mathrm{EC}_{50}=4.8 \mu \mathrm{M}\right.$, data not shown) elevation of intracellular $\mathrm{Ca}^{2+}$ in HEK-293 cells stably transfected with the human recombinant TRPV1 channel with a very low efficacy $(14.96 \pm 0.03 \%$ of $4 \mu \mathrm{M}$ ionomycin at $10 \mu \mathrm{M}$ while at the same concentration, capsaicin was $78.6 \pm 2.4 \%$ ). In contrast, compounds $\mathbf{1}-\mathbf{6}$ showed a potent activating activity on the rat TRPA1 
channel (Table 1). Using a fluorometric test, we observed that rat TRPA1-HEK293 cells exhibited an increase in intracellular $\left[\mathrm{Ca}^{2+}\right]_{\mathrm{i}}$ upon application of 1-6. All compounds showed a potency in the range 2.5-10 $\mu \mathrm{M}$ with the completely saturated analogue 5 being the most potent compound of the series $\left(\mathrm{EC}_{50}=2.6 \mu \mathrm{M}\right)$, while its acetylated analogue 6 was the less potent compound with an about four times reduction of the activity. The activity of the compounds was normalised to the maximum intracellular $\mathrm{Ca}^{2+}$ elevation generated by application of allylisothiocyanate (AITC) $100 \mu \mathrm{M}$. Almost all the compounds (with exception of 5) were able to reach the maximal response of AITC, which was markedly overcome by peracetylated leucettamol A (2).

Table 1. Efficacy and potency of compounds 1-6 on TRPA1 channel and inhibitory (Inh.) effect on TRPM8 channel.

\begin{tabular}{ccccc}
\hline & $\begin{array}{c}\text { Potency EC } \\
\text { TRPA1 }(\boldsymbol{\mu M})\end{array}$ & $\begin{array}{c}\text { Efficacy TRPA1 } \\
(\mathbf{\%} \text { AITC 100 } \boldsymbol{\mu M})\end{array}$ & $\begin{array}{c}\text { IC }_{\mathbf{5 0}} \\
\text { Inh. TRPA1 } \boldsymbol{\mu M} \\
(\text { AITC 100 } \boldsymbol{\mu M})\end{array}$ & $\begin{array}{c}\text { IC }_{\mathbf{5 0}} \\
\text { Inh. TRPM8 } \boldsymbol{\mu M} \\
\text { (icilin 0.25 } \boldsymbol{\mu M} \text { ) }\end{array}$ \\
\hline Leucettamol A (1) & $3.7 \pm 1.7$ & $101.9 \pm 12.4$ & $4.7 \pm 0.2$ & $6.5 \pm 0.3$ \\
$\mathbf{2}$ & $9.4 \pm 2.2$ & $139.2 \pm 7.5$ & $11.6 \pm 2.3$ & $44.6 \pm 10.1$ \\
Leucettamol B (3) & $5.9 \pm 1.9$ & $103.3 \pm 10.6$ & $4.7 \pm 0.9$ & $6.4 \pm 1.0$ \\
$\mathbf{4}$ & $3.5 \pm 2.5$ & $109.6 \pm 21.0$ & $32.6 \pm 4.8$ & $65.7 \pm 8.6$ \\
$\mathbf{5}$ & $2.6 \pm 0.1$ & $69.2 \pm 0.1$ & $6.5 \pm 0.4$ & $6.5 \pm 0.3$ \\
$\mathbf{6}$ & $9.7 \pm 3.3$ & $100.0 \pm 9.7$ & $12.7 \pm 0.8$ & $29.0 \pm 0.6$ \\
\hline
\end{tabular}

As potent TRPA1 activators, a 5-min preincubation of TRPA1-HEK-293 cells with 1-6 desensitized the channel and prevented the elevation of $\left[\mathrm{Ca}^{2+}\right]_{\mathrm{i}}$ induced by AITC in TRPA1-HEK-293 cells (Table 1 and Figure 1). Peracetylated leucettamol B (4) was the less potent analogue at desensitizing the channel. When tested on TRPM8-HEK-293 cells, compounds 1-6 showed no activating activity up to $100 \mu \mathrm{M}$, but leucettamols $\mathrm{A}$ and $\mathrm{B}$ and the saturated analogue 5, pre-incubated (5 min) with the same cells, proved to be potent inhibitors of the activation of TRPM8 by icilin $(0.25 \mu \mathrm{M})$. All the acetylated analogues $(2,4,6)$ were markedly less active (Table 1 and Figure 2).

The activity of leucettamol A (1) is practically identical to that of leucettamol B (3) on both TRPA1 and TRPM8 channels, indicating that the integrity of the double bond system is not required for activity. Accordingly, the completely saturated analogue 5, whose activity at TRPM8 is almost identical to that of its parent compound 1, while it exhibited only a $30 \%$ reduction of efficacy at TRPA1. Anandamide and NADA have been reported to antagonize TRPM8 [32] but the activity of compound 5 demonstrates that the double bond system is likely not required for this activity. Compounds 2, 4, and 6 revealed that the effect of acetylation can be considered moderate as for interaction with TRPA1, since the potency of the acetylated analogues experiences an average reduction by one half, but the efficacy of these compounds is practically unchanged and the peracetylated leucettamol (2) is the most efficacious compound of the series. In contrast, the effect of acetylation on TRPM8 inhibition is more dramatic and all the peracetylated compounds are 5-10 times less active than their parent compounds. 
Figure 1. Desensitization of TRPA1-HEK-293 as a result of 5-min pre-incubation of cells with 1-6. These compounds prevented the elevation of $\left[\mathrm{Ca}^{2+}\right]_{\mathrm{i}}$ induced by AITC $100 \mu \mathrm{M}$ in a concentration-dependent manner. Responses were measured as peak increases in fluorescence and expressed as percentages of the uninhibited response.

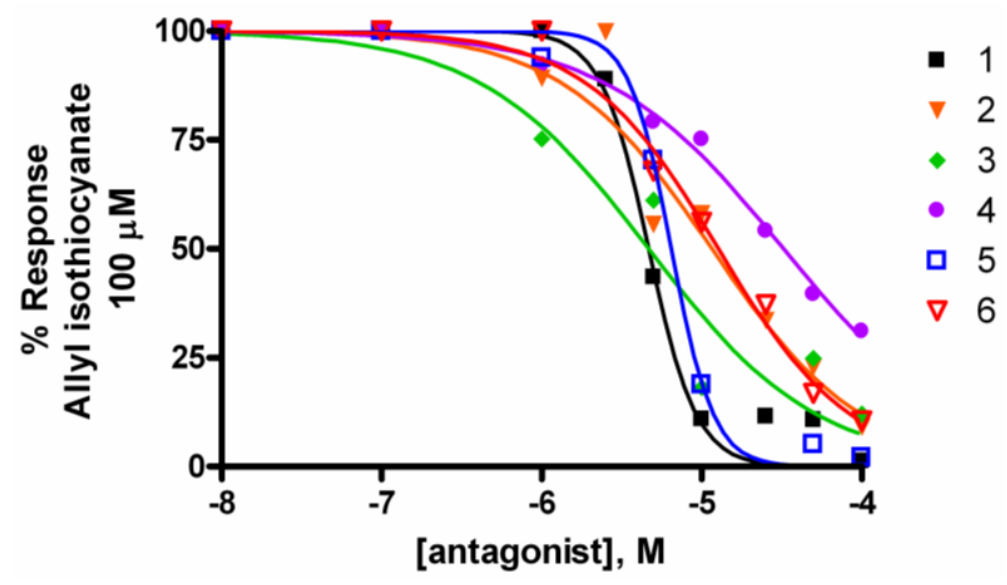

Figure 2. Inhibition of TRPM8-HEK-293 as a result of 5-min pre-incubation of cells with 1-6. These compounds prevented the elevation of $\left[\mathrm{Ca}^{2+}\right]_{\mathrm{i}}$ induced by icilin $0.25 \mu \mathrm{M}$ in a concentration-dependent manner. Responses were measured as peak increases in fluorescence and expressed as percentages of the uninhibited response.

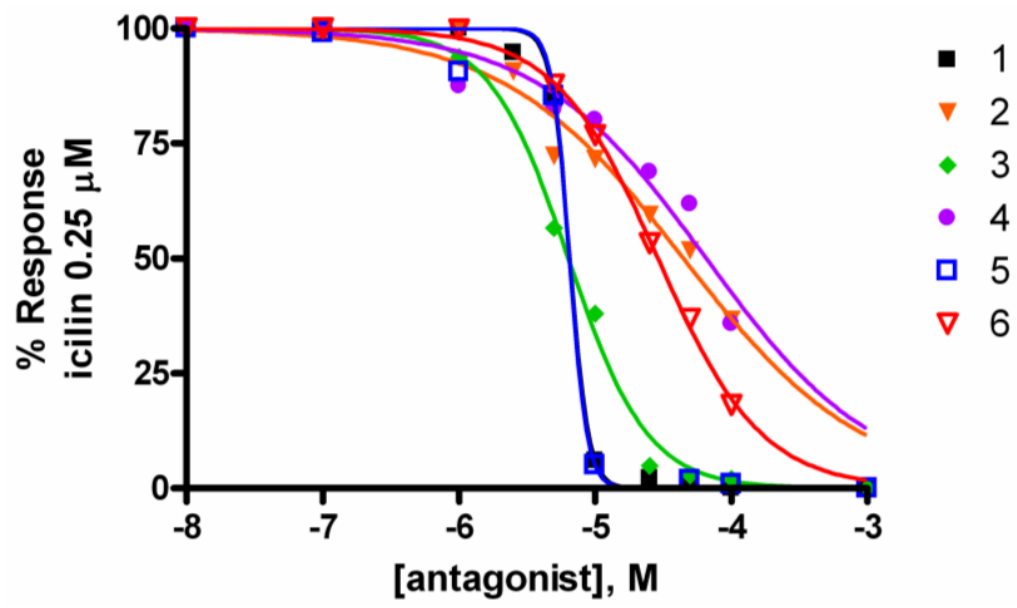

Isothiocyanates, sulfinates and unsaturated aldehydes (as acrolein or cynnamaldehyde) are the archetypal activators of TRPA1. These compounds, as most of the known TRPA1 agonists, are believed to act via the formation of a reversible covalent bond with the thiol (cysteine) residues present in the ankyrin domain, as a result of a Michael-type reaction of their electrophilic carbon or sulfur atoms. In this regard, we have recently reported a simple NMR assay to identify and discriminate among reversible and irreversible thiol sinks [23] and those phytochemicals reacting efficiently with the model compound cysteamine proved to be also able to link and activate the TRPA1 channel [23]. Interestingly, leucettamols are new members of the small class of non-electrophilic agonists of TRPA1 and their activity in the low micromolar range is also remarkable.

The effect of leucettamols on TRPM8 channels is even more interesting. Indeed, while many agonists of TRPM8 have been described, there are very few channel antagonists reported in the 
literature, and among those reported, many also act on other somatosensory-related ion channels, such as TRPV1, suggesting a conserved mechanism amongst these channels. The reported TRPM8 antagonists belong to structurally diverse scaffolds, as menthylamides [33] and piperidines [34], but all these compounds are of synthetic origin and, thus, leucettamols can be indicated as the first class of natural products exhibiting activity as TRPM8 inhibitors. Very recently, some natural products have been demonstrated to inhibit different TRPM channels, as waixenicin A (TRPM7) [35] and quinine (TRPM7 [36] and TRPM5 [37]).

An interesting question stimulated by our discovery concerns the role of leucettamols in the producing organism. It should be noted that these compounds are major secondary metabolites of a sponge Leucetta sp. (about $6 \%$ of the organic extract) and, most likely, they have an important ecological role for the survival of this organism. Our discovery that leucettamols interact with TRP channels could provide a clue to shed light on this point, since they could play a defensive role against predators through production of pro-nociceptive actions on sensory neurons. This hypothesis is in line with the evidence that cnidarian venom causes erythema, burning pain, hypersensitivity and inflammation, through desensitization of TRPV1 both in humans and fishes [38]. Similarly, the polyether toxins gambierol and brevetoxin, which are believed to underlie ciguatera fish poisoning and neurotoxic shellfish poisoning, increase currents through pre-activated TRPV1 channels [39].

\section{Experimental Section}

\subsection{General Experimental Procedures}

Optical rotations $\left(\mathrm{CHCl}_{3}\right)$ were measured at $589 \mathrm{~nm}$ on a $\mathrm{P} 2000$ Jasco polarimeter using a $10 \mathrm{~cm}$ microcell. ${ }^{1} \mathrm{H}(500 \mathrm{MHz})$ and ${ }^{13} \mathrm{C}(125 \mathrm{MHz}) \mathrm{NMR}$ spectra were measured on a Varian INOVA spectrometer. Chemical shifts were referenced to the residual solvent signal $\left(\mathrm{CDCl}_{3}: \delta_{\mathrm{H}} 7.26, \delta_{\mathrm{C}} 77.0\right)$. Homonuclear ${ }^{1} \mathrm{H}$ connectivities were determined by the COSY experiment; one-bond heteronuclear ${ }^{1} \mathrm{H}-{ }^{13} \mathrm{C}$ connectivities by the HSQC experiment; two- and three-bond ${ }^{1} \mathrm{H}-{ }^{13} \mathrm{C}$ connectivities by gradient-HMBC experiments optimized for a ${ }^{2,3} J$ of $8 \mathrm{~Hz}$. Mass spectra were obtained on a LTQ OrbitrapXL (Thermo Scientific) mass spectrometer. Medium pressure liquid chromatography was performed on a Büchi apparatus using a silica gel (230-400 mesh) column; HPLC were achieved on a Knauer apparatus equipped with a refractive index detector. The Knauer HPLC apparatus was used to purify and assess purity ( $>95 \%$ ) of all final products. LUNA (Phenomenex) columns (reverse phase, RP18, or normal phase, SI60, $250 \times 4 \mathrm{~mm}$ ) were used.

\subsection{Animal Material, Extraction and Isolation}

Specimens of Leucetta sp. (310 g wet weight) were collected in January 2010 in the Bunaken Marine Park of Manado along the coasts of the small island of Siladen (North Sulawesi, Indonesia) at a depth of 2-5 m. A voucher sample (MAN-10-08) was deposited at the Dipartimento di Scienze del Mare, Università Politecnica delle Marche.

The sponge was repeatedly extracted with $\mathrm{MeOH}$ and $\mathrm{CHCl}_{3}$ at room temperature and the obtained combined material $(8.6 \mathrm{~g})$ was partitioned between $\mathrm{H}_{2} \mathrm{O}$ and EtOAc to give an acetate extract $(0.45 \mathrm{~g})$, while the water phase was further partitioned against $n-\mathrm{BuOH}$, thus affording a butanol extract (1.2 g). 
This was chromatographed by MPLC over silica gel (230-400 mesh) eluting with a gradient system of increasing polarity from EtOAc to $\mathrm{MeOH}$. Fractions eluted with EtOAc/MeOH 7:3 were further purified by RP18 HPLC (MeOH/ $\left.\mathrm{H}_{2} \mathrm{O} 55: 45\right)$ to afford leucettamols $\mathrm{A}(\mathbf{1}, 452.0 \mathrm{mg})$ and $\mathrm{B}(\mathbf{3}, 45.5 \mathrm{mg})$ in the pure state.

\subsection{Acetylation of Leucettamols}

Leucettamol A $(1,15.0 \mathrm{mg}, 0.032 \mathrm{mmol})$ was dissolved in dry pyridine $(1.5 \mathrm{~mL})$ and treated with $\mathrm{Ac}_{2} \mathrm{O}(1.5 \mathrm{~mL})$. After standing overnight under stirring at room temp, the reaction was worked up by addition of a few drops methanol to destroy the excess $\mathrm{Ac}_{2} \mathrm{O}$, water $(c a .1 \mathrm{~mL})$ and EtOAc $(c a .3 \mathrm{~mL})$. The organic phase was washed sequentially with $2 \mathrm{~N} \mathrm{H}_{2} \mathrm{SO}_{4}$, sat. $\mathrm{NaHCO}_{3}$ and brine. After drying $\left(\mathrm{Na}_{2} \mathrm{SO}_{4}\right)$ and removal of the solvent, the residue was purified by HPLC ( $n$-hexane/EtOAc 85:15) to afford $13.5 \mathrm{mg}$ ( $66 \%$ yield) of the tetra-acetate 2 , identified by comparison with data reported in [30]. When leucettamol B (3, $5.0 \mathrm{mg}, 0.010 \mathrm{mmol})$ was subjected to the same reaction procedure, $4.5 \mathrm{mg}$ (64\% yield) of the penta-acetylated derivative 4 were obtained. Compound $4:{ }^{1} \mathrm{H}$ NMR (500 MHz, $\left.\mathrm{CDCl}_{3}\right): \delta 6.20(1 \mathrm{H}, \mathrm{dd}, J=15.0$ and $11.0 \mathrm{~Hz}, H-10), 5.80(1 \mathrm{H}, \mathrm{dd}, J=15.0$ and $6.0 \mathrm{~Hz}, H-9)$, 5.45-5.40 (10H, overlapped, $H-5, H-6, H-11, H-12, H-14, H-15, H-17, H-18, H-20, H-21), 4.93(1 \mathrm{H}$, m, $H-8), 4.83(2 \mathrm{H}, \mathrm{m}, H-3$ and $H-28), 4.18(2 \mathrm{H}, \mathrm{m}, H-2$ and $H-29), 2.80\left(4 \mathrm{H}, \mathrm{m}, H_{2}-4\right.$ and $\left.H_{2}-7\right), 2.75$ (6H, m, $H_{2}-13, H_{2}-16$ and $\left.H_{2}-19\right), 2.10-2.05(15 \mathrm{H}, \mathrm{s}, 5 \times A c), 2.04\left(2 \mathrm{H}, \mathrm{m}, H_{2}-22\right), 1.50-1.40(10 \mathrm{H}, \mathrm{m}$, $H_{2}-23$ to $\left.H_{2}-27\right), 1.16(6 \mathrm{H}, \mathrm{d}, J=6.9 \mathrm{~Hz}, M e-1$ and $M e-30)$. ESIMS (positive ions): $\mathrm{m} / z 721[\mathrm{M}+\mathrm{Na}]^{+}$.

\subsection{Reduction of Leucettamol A and Acetylation of Compound $\mathbf{5}$}

Leucettamol A (1, 34.0 mg) was treated with palladium-charcoal in EtOH $(6 \mathrm{~mL})$ under a hydrogen atmosphere at room temperature for $18 \mathrm{~h}$. After filtration of the catalyst, the solvent was evaporated and the residue was purified by RP18 HPLC $\left(\mathrm{MeOH} / \mathrm{H}_{2} \mathrm{O}\right.$ 7:3) to give the saturated compound 5 (36.5 mg, 100\%), whose spectroscopic data were identical with those reported in [30]. Compound 5 $(8.0 \mathrm{mg}, 0.016 \mathrm{mmol})$ was subjected to acetylation following the same procedure described below and gave compound $6(10.5 \mathrm{mg})$ in quantitative yields. Compound 6: ${ }^{1} \mathrm{H}$ NMR $\left(500 \mathrm{MHz}, \mathrm{CDCl}_{3}\right): \delta 4.82$ (2H, m, $H-3$ and $H-28), 4.16(2 \mathrm{H}, \mathrm{m}, H-2$ and $H-29), 2.09(6 \mathrm{H}, \mathrm{s}, O A c), 1.96(6 \mathrm{H}, \mathrm{s}, O A c), 1.58-1.48$ (4H, m, $H_{2}-4$ to $\left.H_{2}-27\right), 1.25-1.20\left(42 \mathrm{H}, H_{2}-5\right.$ to $\left.H_{2}-26\right), 1.15(6 \mathrm{H}, \mathrm{d}, J=6.9 \mathrm{~Hz}, M e-1$ and $M e-30)$. ESIMS (positive ions): $m / z 675[\mathrm{M}+\mathrm{Na}]^{+}$.

\subsection{In Vitro Assays with TRP Receptors}

Assays of TRP-mediated elevation of intracellular $\left[\mathrm{Ca}^{2+}\right]$ were performed as previously described [40]. In the current study we have used wild-type HEK293 cells, cells stably expressing rat TRPA1 or human TRPV1 or rat TRPM8. HEK-293 cells stably over-expressing recombinant rat TRPA1, rat TRPM8 or human TRPV1 were selected by G-418 (Geneticin; $600 \mu \mathrm{g} \cdot \mathrm{mL}^{-1}$ ), grown on $100 \mathrm{~mm}$ diameter Petri dishes as monolayers in minimum essential medium supplemented with non-essential amino acids, $10 \%$ fetal bovine serum and $2 \mathrm{mM}$ glutamine, and maintained under $5 \% \mathrm{CO}_{2}$ at $37{ }^{\circ} \mathrm{C}$. Stable expression of each channel was confirmed by real time quantitative PCR (not shown) $[32,41,42]$. On the day of the experiment, the cells were loaded for $1 \mathrm{~h}$ at $25^{\circ} \mathrm{C}$ with the 
cytoplasmic calcium indicator Fluo-4AM (Invitrogen Carlsbad, CA, USA) $4 \mu \mathrm{M}$ in DMSO containing 0.02\% Pluronic F-127 (Invitrogen, Carlsbad, CA, USA). After loading, cells were washed twice in Tyrode's buffer (145 mM NaCl, $2.5 \mathrm{mM} \mathrm{KCl}, 1.5 \mathrm{mM} \mathrm{CaCl}_{2}, 1.2 \mathrm{mM} \mathrm{MgCl}$, $10 \mathrm{mM}$ D-glucose and $10 \mathrm{mM}$ HEPES, $\mathrm{pH}$ 7.4), re-suspended in the same buffer, and transferred to the quartz cuvette of the spectrofluorimeter $\left(\lambda_{\mathrm{ex}}=488 \mathrm{~nm} ; \lambda_{\mathrm{em}}=516 \mathrm{~nm}\right.$ ) (Perkin-Elmer LS50B equipped with PTP-1 Fluorescence Peltier System; Perkin-Elmer Life and Analytical Sciences, Waltham, MA, USA) under continuous stirring. About 100,000 cells were used for each data point. Experiments were carried out at $22{ }^{\circ} \mathrm{C}$ by measuring cell fluorescence before and after the addition of various concentrations of test compounds. The values of the effect on $\left[\mathrm{Ca}^{2+}\right]_{\mathrm{i}}$ in wild-type (i.e., not transfected with any construct) HEK-293 cells were taken as baselines and subtracted from the values obtained from transfected cells. The potency of test compounds $\left(\mathrm{EC}_{50}\right.$ values) was determined as the concentration of test substances required to produce half-maximal increases in $\left[\mathrm{Ca}^{2+}\right]_{\mathrm{i}}$. The efficacy of the agonists on TRPA1 is expressed as a percentage of the effect obtained with $100 \mu \mathrm{M}$ allylisothiocyanate (AITC). Antagonist/desensitizing behaviour was evaluated against icilin $(0.25 \mu \mathrm{M})$ for TRPM8 and AITC $(100 \mu \mathrm{M})$ for TRPA1 by adding the compounds in the quartz cuvette 5 min before stimulation of cells with agonists. Data are expressed as the concentration exerting a half-maximal inhibition of agonist effect $\left(\mathrm{IC}_{50}\right)$. All determinations were at least performed in triplicate. Dose-response curves were fitted by a sigmoidal regression with variable slope. Curve fitting and parameter estimation were performed with GraphPad Prism (GraphPad Software Inc., San Diego, CA, USA).

\section{6. $C B_{1}$ and $C B_{2}$ Receptor Binding Assays}

Membranes harvested from human recombinant $\mathrm{CB}_{1}\left(\mathrm{~B}_{\max }=2.5 \mathrm{pmol} / \mathrm{mg}\right.$ protein $)$ or $\mathrm{CB}_{2}$ $\left(\mathrm{B}_{\max }=4.7 \mathrm{pmol} / \mathrm{mg}\right.$ protein) receptor-transfected HEK-293 cells were incubated with the high-affinity ligand $\left[{ }^{3} \mathrm{H}\right]-\mathrm{CP}-55,940\left(0.14 \mathrm{nM}, K_{\mathrm{d}}=0.18\right.$ or $0.084 \mathrm{nM}, K_{\mathrm{d}}=0.31 \mathrm{nM}$, respectively, for $\mathrm{CB}_{1}$ and $\left.\mathrm{CB}_{2}\right)$, and displaced with $10 \mu \mathrm{M}$ of the heterologous competitor for nonspecific binding, WIN-55212-2 ( $K_{\mathrm{i}}$ values 9.2 and $2.1 \mathrm{nM}$, respectively, for $\mathrm{CB}_{1}$ and $\mathrm{CB}_{2}$ ). All compounds were assayed according to the manufacturer's (Perkin-Elmer, Milano, Italy) instructions. Increasing concentrations of compounds were incubated with $\left[{ }^{3} \mathrm{H}\right]-\mathrm{CP}-55,940$ for $90 \mathrm{~min}$ at $30{ }^{\circ} \mathrm{C}$ to generate displacement curves. $\mathrm{IC}_{50}$ values of the test compounds for the displacement of the bound radioligand were obtained by GraphPad Prism and used to calculate $K_{\mathrm{i}}$ values via the Cheng-Prusoff equation. Data are represented as means of at least $n=3$ experiments.

\section{Conclusions}

The current knowledge of TRP channels is strongly indebted to the basic research in the field of natural products chemistry and the biological evaluation of several naturally occurring substances, especially from plants, has been a driving force for the characterization of many TRP channels. For example, attempts to understand the hot and painful action of capsaicin and of its ultrapotent analogue resiniferatoxin, led to the cloning of the vanilloid channel TRPV1 [5]. More recently, two additional TRP channels, TRPM8 and TRPA1, have been identified as novel and potentially useful targets for the treatment of several pathological conditions and, they currently represent a hot topic of the research in this field. 
In this paper we have reported that leucettamols, bifunctionalized sphingoid-like compounds of marine origin, act as activators of the TRPA1 channel and inhibitors of the icilin-mediated activation of the TRPM8 channel. To our knowledge, leucettamols represent the first compounds of marine origin to target TRPA1 and/or TRPM8 channels. Although leucettamols bear a structural resemblance with anandamide, including also the cis double bond system required to adopt the bent U-shaped conformation, they proved to be completely inactive at $\mathrm{CB}_{1}$ and $\mathrm{CB}_{2}$ receptors. They were also inactive toward TRPV1 channels (only leucettamol B showed a very modest activity).

Leucettamols belong to a somewhat rare class of natural products and, to date, only a handful of two-headed sphingoid-like compounds have been found in nature, mostly from marine sponges, including rhizochalins [43-46], ocenapiside [47], and calyxoside [48]. These compounds differ from leucettamols in the length/functionalization of the chain and/or in the configuration at the stereogenic centers and it would be very interesting to test them on TRP channels. Moreover, the relatively simple structure of leucettamols, especially that of the fully saturated semi-synthetic analogue 5, should guarantee the feasibility of a total chemical synthesis, thus allowing a more detailed evaluation of this new class of TRP ligands as a possible approach for the treatment of neuropathic and inflammatory pain and of prostate cancer.

\section{Acknowledgments}

This research was partially conducted during the Master Course "Tropical Marine Biodiversity and Natural Products" of Università Politecnica delle Marche. Mass and NMR spectra were recorded at "Centro di Servizio Interdipartimentale di Analisi Strumentale", Università di Napoli "Federico II".

\section{References}

1. Clapham, D.E. TRP channels as cellular sensors. Nature 2003, 426, 517-524.

2. Montell, C.; Birnbaumer, L.; Flockerzi, V.; Bindels, R.J.; Bruford, E.A.; Caterina, M.J.; Clapham, D.E.; Harteneck, C.; Heller, S.; Julius, D.; et al. A unified nomenclature for the superfamily of TRP cation channels. Mol. Cell 2002, 9, 229-231.

3. Montell, C.; Birnbaumer, L.; Flockerzi, V. The TRP channels, a remarkably functional family. Cell 2002, 108, 595-598.

4. Zhang, Y.; Hoon, M.A.; Chandrashekar, J.; Mueller, K.L.; Cook, B.; Wu, D.Q.; Zuker, C.S.; Ryba, N.J.P. Coding of sweet, bitter, and umami tastes: Different receptor cells sharing similar signaling pathways. Cell 2003, 112, 293-301.

5. Caterina, M.J.; Schumacher, M.A.; Tominaga, M.; Rosen, T.A.; Levine, J.D.; Julius, D. The capsaicin receptor, a heat-activated ion channel in the pain pathway. Nature 1997, 389, 816-824.

6. Nilius, B.; Owsianik, G.; Voets, T.; Peters, J.A. Transient receptor potential cation channels in disease. Physiol. Rev. 2007, 87, 165-217.

7. Appendino, G.; Minassi, A.; Pagani, A.; Ech-Chadad, A. The role of natural products in the ligand deorphanization of TRP channels. Curr. Pharm. Des. 2008, 14, 2-17.

8. Baraldi, P.G.; Preti, D.; Materazzi, S.; Geppetti, P. Transient receptor potential ankyrin 1 (TRPA1) channel as emerging target for novel analgesics and anti-inflammatory agents. J. Med.

Chem. 2010, 53, 5085-5107. 
9. Knowlton, W.M.; Bifolck-Fischer, A.; Bautista, D.M.; McKemy, D.D. TRPM8, but not TRPA1, is required for neural and behavioral responses to acute noxious cold temperatures and cold-mimetics in vivo. Pain 2010, 150, 340-350.

10. Brignell, J.L.; Chapman, V.; Kendall, D.A. Comparison of icilin- and cold-evoked responses of spinal neurones, and their modulation of mechanical activity, in a model of neuropathic pain. Brain Res. 2008, 1215, 87-96.

11. Harrington, A.M.; Hughes, P.A.; Martin, C.M.; Yang, J.; Castro, J.; Isaacs, N.J.; Blackshaw, L.A.; Brierley, S.M. A novel role for TRPM8 in visceral afferent function. Pain 2011, 152, 1459-1468.

12. Zhang, L.; Barritt, G.J. TRPM8 in prostate cancer cells: A potential diagnostic and prognostic marker with a secretory function? Endocr. Relat. Cancer 2006, 13, 27-38.

13. Zhang, L.; Barritt, G.J. Evidence that TRPM8 is an androgen-dependent $\mathrm{Ca}^{2+}$ channel required for the survival of prostate cancer cells. Cancer Res. 2004, 64, 8365-8373.

14. Meves, H. Arachidonic acid and ion channels: An update. Br. J. Pharmacol. 2008, 155, 4-16.

15. Hofmann, T.; Obukhov, A.G.; Schaefer, M.; Harteneck, C.; Gudermann, T.; Schultz, G. Direct activation of human TRPC6 and TRPC3 channels by diacylglycerol. Nature 1999, 397, 259-263.

16. Vetter, I.; Lewis, R.J. Natural product ligands of TRP channels. Adv. Exp. Med. Biol. 2011, 704, 41-85.

17. Bandell, M.; Story, G.M.; Hwang, S.W.; Viswanath, V.; Eid, S.R.; Petrus, M.J.; Earley, T.J.; Patapoutian, A. Noxious cold ion channel TRPA1 is activated by pungent compounds and bradykinin. Neuron 2004, 41, 849-857.

18. Bautista, D.M.; Siemens, J.; Glazer, J.M.; Tsuruda, P.R.; Basbaum, A.I.; Stucky, C.L.; Jordt, S.E.; Julius, D. The menthol receptor TRPM8 is the principal detector of environmental cold. Nature 2007, 448, 204-208.

19. Costa, B.; Giagnoni, G.; Franke, C.; Trovato, A.E.; Colleoni, M. Vanilloid TRPV1 receptor mediates the anti-hyperalgesic effect of the non-psychoactive cannabinoid, cannabidiol, in a rat model of acute inflammation. Br. J. Pharmacol. 2004, 143, 247-250.

20. Watanabe, H.; Vriens, J.; Prenen, J.; Droogmans, G.; Voets, T.; Nilius, B. Anandamide and arachidonic acid use epoxyeicosatrienoic acids to activate TRPV4 channels. Nature 2003, 424, 434-438.

21. Bassoli, A.; Borgonovo, G.; Caimi, S.; Scaglioni, L.; Morini, G.; Moriello, A.S.; Di Marzo, V.; de Petrocellis, L. Taste-guided identification of high potency TRPA1 agonists from Perilla frutescens. Bioorg. Med. Chem. 2009, 17, 1636-1639.

22. Appendino, G.; Ligresti, A.; Minassi, A.; Cascio, M.G.; Allarà, M.; Taglialatela-Scafati, O.; Pertwee, R.G.; de Petrocellis, L.; Di Marzo, V. Conformationally constrained fatty acid ethanolamides as cannabinoid and vanilloid receptor probes. J. Med. Chem. 2009, 52, 3001-3009.

23. Avonto, C.; Taglialatela-Scafati, O.; Pollastro, F.; Minassi, A.; Di Marzo, V.; de Petrocellis, L.; Appendino, G. An NMR spectroscopic method to identify and classify thiol-trapping agents: Revival of Michael acceptors for drug discovery? Angew. Chem. Int. Ed. 2011, 50, 467-471.

24. Nassini, R.; Materazzi, S.; Vriens, J.; Prenen, J.; Benemei, S.; de Siena, G.; La Marca, G.; Andrè, E.; Preti, D.; Avonto, C.; et al. The "headache tree", via umbellulone and TRPA1, activates the trigeminovascular system. Brain 2012, 135, 376-390. 
25. Chianese, G.; Fattorusso, E.; Taglialatela-Scafati, O.; Bavestrello, G.; Calcinai, B.; Dien, H.A.; Ligresti, A.; Di Marzo, V. Desulfohaplosamate, a new phosphate-containing steroid from Dasychalina sp., is a selective cannabinoid $\mathrm{CB}_{2}$ receptor ligand. Steroids 2011, 76, 998-1002.

26. Fattorusso, C.; Persico, M.; Calcinai, B.; Cerrano, C.; Parapini, S.; Taramelli, D.; Novellino, E.; Romano, A.; Scala, F.; Fattorusso, E.; et al. Manadoperoxides A-D from the Indonesian sponge Plakortis cfr. Simplex: Further insights on the structure-activity relationships of simple 1,2-dioxane antimalarials. J. Nat. Prod. 2010, 73, 1138-1145.

27. Fattorusso, E.; Romano, A.; Taglialatela-Scafati, O.; Irace, C.; Maffettone, C.; Bavestrello, G.; Cerrano, C. Oxygenated cembranoids of the decaryiol type from the Indonesian soft coral Lobophytum sp. Tetrahedron 2009, 65, 2898-2904.

28. Fattorusso, E.; Luciano, P.; Putra, M.Y.; Taglialatela-Scafati, O.; Ianaro, A.; Panza, E.; Bavestrello, G.; Cerrano, C. Chloroscabrolides, chlorinated norcembranoids from the Indonesian soft coral Sinularia sp. Tetrahedron 2011, 67, 7983-7988.

29. Kong, F.H.; Faulkner, D.J. Leucettamines A and B, two antimicrobial lipids from the calcareous sponge Leucetta microraphis. J. Org. Chem. 1993, 58, 970-971.

30. Tsukamoto, S.; Takeuchi, T.; Rotinsulu, H.; Mangindaan, R.E.P.; van Soest, R.W.M.; Ukai, K.; Kobayashi, H.; Namikoshi, M.; Ohta, T.; Yokosawa, H. Leucettamol A: A new inhibitor of Ubc13-Uev1A interaction isolated from a marine sponge, Leucetta aff. microrhaphis. Bioorg. Med. Chem. Lett. 2008, 18, 6319-6320.

31. Dalisay, D.S.; Tsukamoto, S.; Molinski, T.F. Absolute configuration of the $\alpha, \omega$-bifunctionalized sphingolipid leucettamol A from Leucetta microrhaphis by deconvoluted exciton coupled CD. J. Nat. Prod. 2009, 72, 353-359.

32. De Petrocellis, L.; Starowicz, K.; Moriello, A.S.; Vivese, M.; Orlando, P.; Di Marzo, V. Regulation of transient receptor potential channels of melastatin type 8 (TRPM8): Effect of cAMP, cannabinoid CB(1) receptors and endovanilloids. Exp. Cell Res. 2007, 313, 1911-1920.

33. Ortar, G.; de Petrocellis, L.; Morera, L.; Moriello, A.S.; Orlando, P.; Morera, E.; Nalli, M.; Di Marzo, V. (-)-Menthylamine derivatives as potent and selective antagonists of transient receptor potential melastatin type-8 (TRPM8) channels. Bioorg. Med. Chem. Lett. 2010, 20, 2729-2732.

34. Tamayo, N.A.; Bo, Y.; Gore, V.; Ma, V.; Nishimura, N.; Tang, P.; Deng, H.; Klionsky, L.; Lehto, S.G.; Wang, W.; et al. Fused piperidines as a novel class of potent and orally available transient receptor potential melastatin type 8 (TRPM8) antagonists. J. Med. Chem. 2012, 55, 1593-1611.

35. Zierler, S.; Yao, G.; Zhang, Z.; Kuo, W.C.; Poerzgen, P.; Penner, R.; Horgen, F.D.; Fleig, A. Waixenicin A inhibits cell proliferation through magnesium-dependent block of transient receptor potential melastatin 7 (TRPM7) channels. J. Biol. Chem. 2011, 286, 39328-39335.

36. Chubanov, V.; Mederos y Schnitzler, M.; Meisner, M.; Schafer, S.; Abstiens, K.; Hofmann, T.; Gudermann, T. Natural and synthetic modulators of SK (Kca2) potassium channels inhibit magnesium-dependent activity of the kinase-coupled cation channel TRPM7. Br. J. Pharmacol. 2012, 166, 1357-1376. 
37. Talareva, K.; Yasumatsu, K.; Yoshida, R.; Margolskee, R.F.; Voets, T.; Ninomiya, Y.; Nilius, B. The taste transduction channel: TRPM5 is a locus for bitter-sweet taste interactions. FASEB J. 2008, 22, 1343-1355.

38. Cuypers, E.; Yanagihara, A.; Karlsson, E.; Tytgat, J. Jellyfish and other cnidarian envenomations cause pain by affecting TRPV1 channels. FEBS Lett. 2006, 580, 5728-5732.

39. Cuypers, E.; Yanagihara, A.; Rainier, J.D.; Tytgat, J. TRPV1 as a key determinant in ciguatera and neurotoxic shellfish poisoning. Biochem. Biophys. Res. Commun. 2007, 361, 214-217.

40. De Petrocellis, L.; Ligresti, A.; Moriello, A.S.; Allarà, M.; Bisogno, T.; Petrosino, S.; Stott, C.G.; Di Marzo, V. Effects of cannabinoids and cannabinoid-enriched Cannabis extracts on TRP channels and endocannabinoid metabolic enzymes. Br. J. Pharmacol. 2011, 163, 1479-1494.

41. De Petrocellis, L.; Bisogno, T.; Davis, J.B.; Pertwee, R.G.; Di Marzo, V. Overlap between the ligand recognition properties of the anandamide transporter and the VR1 vanilloid receptor: Inhibitors of anandamide uptake with negligible capsaicin-like activity. FEBS Lett. 2000, 483, $52-56$.

42. De Petrocellis, L.; Vellani, V.; Schiano-Moriello, A.; Marini, P.; Magherini, P.C.; Orlando, P.; Di Marzo, V. Plant-derived cannabinoids modulate the activity of transient receptor potential channels of ankyrin type-1 and melastatin type-8. J. Pharmacol. Exp. Ther. 2008, 325, 1007-1015.

43. Makarieva, T.N.; Denisenko, V.A.; Stonik, V.A.; Milgrom, Y.N.; Rashkes, Y.W. Rhizochalin, a novel secondary metabolite of mixed biosynthesis from the sponge Rhizochalina incrustata. Tetrahedron Lett. 1989, 30, 6581-6584.

44. Makarieva, T.N.; Guzii, A.G.; Denisenko, V.A.; Dmitrenok, P.S.; Santalova, E.A.; Pokanevich, E.V.; Molinski, T.F.; Stonik, V.A. Rhizochalin A, a novel two-headed sphingolipid from the sponge Rhizochalina incrustata. J. Nat. Prod. 2005, 68, 255-257.

45. Makarieva, T.N.; Dmitrenok, P.S.; Zakharenko, A.M.; Denisenko, V.A.; Guzii, A.G.; Li, R.; Skepper, C.K.; Molinski, T.F.; Stonik, V.A. Rhizochalins C and D from the sponge Rhizochalina incrustata: A rare threo-sphingolipid and a facile method for determination of the carbonyl position in alpha,omega-bifunctionalized ketosphingolipids. J. Nat. Prod. 2007, 70, 1991-1998.

46. Molinski, T.F.; Makarieva, T.N.; Stonik, V.A. (-)-Rhizochalin is a dimeric enantiomorphic $(2 R)$-sphingolipid: Absolute configuration of pseudo- $C_{2 \mathrm{v}}$-symmetric bis-2-amino-3-alkanols by CD. Angew. Chem. Int. Ed. 2000, 39, 4076-4079.

47. Nicholas, G.M.; Hong, T.W.; Molinski, T.F.; Lerch, M.L.; Cancilla, M.T.; Lebrilla, C.B. Oceanapiside, an antifungal bis- $\alpha, \omega$-amino alcohol glycoside from the marine sponge Oceanapia phillipensis. J. Nat. Prod. 1999, 62, 1678-1681.

48. Zhou, B.N.; Mattern, M.P.; Johnson, R.K.; Kingston, D.G.I. Structure and stereochemistry of a novel bioactive sphingolipid from a Calyx sp. Tetrahedron 2001, 57, 9549-9554.

(C) 2012 by the authors; licensee MDPI, Basel, Switzerland. This article is an open access article distributed under the terms and conditions of the Creative Commons Attribution license (http://creativecommons.org/licenses/by/3.0/). 